\title{
Mapping Cultural Heritage in Coastal Areas with UAS: The Case Study of Lesvos Island
}

\author{
Apostolos Papakonstantinou ${ }^{1}$ (), Dimitris Kavroudakis ${ }^{1}$ (), Yannis Kourtzellis ${ }^{2}$, \\ Michail Chtenellis ${ }^{1}$, Vasilis Kopsachilis ${ }^{1}$, Konstantinos Topouzelis ${ }^{3, * \mathbb{C}}$ and Michail Vaitis ${ }^{1}$ (D) \\ 1 Department of Geography, University of the Aegean, University Hill, Mytilene, 81100 Lesvos, Greece; \\ apapak@geo.aegean.gr (A.P.); dimitrisk@aegean.gr (D.K.); m.chtenellis@gmail.com (M.C.); \\ vkopsachilis@geo.aegean.gr (V.K.); vaitis@aegean.gr (M.V.) \\ 2 Ephorate of Antiquities of Lesvos, Hellenic Ministry of Culture \& Sports, 10 Leondos Sofou Str., Mytilene, \\ 81100 Lesvos, Greece; ikourtzellis@culture.gr \\ 3 Department of Marine Sciences, University of the Aegean, University Hill, Mytilene, 81100 Lesvos, Greece; \\ topouzelis@marine.aegean.gr \\ * $\quad$ Correspondence: topouzelis@marine.aegean.gr; Tel.: +30-22510-36878
}

Received: 31 March 2019; Accepted: 6 May 2019; Published: 12 May 2019

\begin{abstract}
Dynamic processes in coastal zones and human activities in the coastal environment produce pressure on cultural heritage, especially in touristic places. Unmanned aerial systems (UAS) are used as an additional tool for monitoring cultural heritage sites in sensitive coastal areas. UASs provide low-cost accurate spatial data and high-resolution imagery products in various spatial and temporal scales. The use of UAS for mapping cultural heritage sites in the coastal zone is of increasing interest among scientists and archaeologists in terms of monitoring, documentation, mapping, and restoration. This study outlines the integration of UAS data acquisition and structure from motion (SfM) pipeline for the visualization of selected cultural heritage areas (ancient harbors) in the coastal zone. The UAS-SfM methodology produces very detailed orthophoto maps for mapping and detecting cultural heritage sites. Additionally, a metadata cataloging system has been developed in order to facilitate online searching operations for all products of the data acquisition, SfM pipeline, and cartographic processes. For this reason, a specific metadata profile was implemented, based on the European INSPIRE framework. As a result, datasets reusability and catalogs interoperability are promoted.
\end{abstract}

Keywords: cultural heritage areas; coastal cultural heritage monitoring; UAS; UAV-SfM; geographic metadata

\section{Introduction}

Coastal cities that are built on the remains of ancient ones are facing a double challenge. On the one hand, they are required to design a public space according to the current urban planning approaches and policies, and on the other to rescue and, consequently, to enhance cultural heritage $(\mathrm{CH})$. The ancient structures and building stock operate as tangible witnesses of the city's historical development through centuries [1]. Given that the coastal zone of a city is subject to constant changes, the excavation works (usually in the framework of large-scale public work projects) reveal ancient structures designed to facilitate commercial maritime transport operations (harbors, quays and jetties) or defense structures (walls, onshore towers, coastal defense walls, etc.) [2-4]. In addition, the coastal zone accepts more pressure for economic exploitation. During the second half of the 20th century, in many coastal cities, additional public space was created with embankments, and port installations were covering the basins of the ancient harbors and changing the ancient coastline.

In many cases, the combination of natural and anthropogenic structures on the coastal zone, the rising sea level and the partial destruction or embankment of the ancient infrastructures, have 
dramatically changed the old boundaries of coastal cities. Ancient coastal defense walls, artificial breakwaters, and quays "have moved" in relation to the current land, or they are preserved below the actual sea level [5]. Although this displacement is not always clearly defined, there are structural elements on the ancient structures, like lead clamps between the stone plinths (now submerged), which provide an excellent reference for the ancient sea level [6,7].

Excavations in coastal cities call for a multi-disciplinary approach by archaeologists, geologists, geographers, surveyors, and other scientific groups. These scholars need access to accurate spatial data (like high-resolution digital surface models and orthophoto maps), captured with fast procedures and low-cost tools to map or to monitor ancient port installations or other $\mathrm{CH}$ coastal areas. These data should be available in a convenient way through web-based information systems, combining also old findings from previous excavations in the same area.

Traditionally, a variety of remote-sensing data including low-, medium- and high-resolution images (e.g., MODIS; Landsat; QuickBird), as well as ready satellite products (e.g., ASTER Global Digital Elevation Model, ASTER GDEM) were used to extract valuable information regarding natural and anthropogenic hazards as well as to assess the overall risk for $\mathrm{CH}$ sites and monuments [8]. Although the spatial resolution of satellite imagery has significantly improved in the last decade (tens of centimeters), the data collected is still not sufficient to map medium to small characteristics in $\mathrm{CH}$, as centimeter-level accuracy is needed [9]. Furthermore, traditional remote-sensing data are not capable of monitoring small-scale changes due to inherent limitations such as spatial resolution and data volume. Other limitations of the satellite imagery include the way of data acquisition (e.g., stereo or tri-stereo image mode), the difficulty in data acquisition due to satellite installation trajectories and revisiting times in a specific time frame as well as their high cost.

By contrast, unmanned aerial systems (UAS) are able to provide extremely high-resolution images at low cost, but in a limited geographic area [10]. UAS (or drones), consisting of an unmanned aerial vehicle (UAV) and a sensor (e.g., optical sensor, Lidar), provide digital images with spatial and temporal resolutions that can overcome some of the limitations of spatial data acquisition using satellites and manned aerial photography. The use of drones has exploded, because of their agility and quality to map an area with high end-products. They deliver digital images with spatial $(1-5 \mathrm{~cm})$ and temporal resolution superior of satellite imagery, on demand, and most importantly, economically and more reliable than the high-resolution satellite images [11,12]. Currently, a UAS is a viable option for collecting remote sensing data for a wide range of applications, including scientific, agricultural and environmental ones [10,13-17]. In combination with new image-processing algorithms, i.e., structure from motion (SfM), UAS can provide high-resolution geoinformation at a low cost for areas of a small geographical scale $[11,18]$. UAS data acquisition in combination with SfM pipeline consists an efficient, quick and accurate methodology which are used in a plethora of sciences and applications for the creation of geospatial information. The UAS-SfM methodology is used for 2D and 3D visualizations since it enables the development of high-resolution orthophoto maps, accurate digital surface models (DSM) and digital terrain models (DTM), and finally very detailed 3D models of the study area [19-25]. Furthermore, scientists are using UAS-SfM methodology for mapping and detecting; cultural sites, coastline changes, coastal erosion and the human pressure in the coastal zone $[9,26,27]$.

The large volume of images acquired for UAS surveys, introduces new needs, leading to the creation of new methods and tools for effective data organization, management and retrieval [28]. A key issue regarding information systems for such purposes is the definition and incorporation of metadata profiles in accordance with the application domain [29-31]. Since all data are geo-referenced, metadata standards for geospatial information could be adopted [32]. In addition, certain extensions are needed in order to explicitly introduce metadata elements (required for retrieval operations) that are usually "hidden" in other elements in the geospatial metadata standards. For example, UAS mission information should explicitly accompany the photographs taken, instead of being included in other metadata elements, like abstract or description. 
The contribution of the work presented in this paper is twofold. Firstly, we describe the production of high-resolution 3D visualizations for two $\mathrm{CH}$ areas on Lesvos Island, Greece: the ancient harbors of Mytilene and Eresos cities. The SfM methodology was applied to photographs captured from UAS. Examination and analysis of the output images produced by the UAS-SfM methodology, revealed for the first-time unknown aspects, such as the detailed geometry of the ancient installations, their real dimensions, the state of preservation (destruction, repairs, structural phases, etc.) and their relation with the city's coastal monuments (streets, defense walls, agora, sanctuaries, cemeteries, etc.).

Secondly, we describe the development of a metadata cataloging system dedicated to UAS-acquired photographs and secondary products. The system incorporates an extension of the INSPIRE Metadata Regulation [33,34] and is based on the open source ESRI Geoportal Server platform. In this way, all datasets related to a $\mathrm{CH}$ area are available for discovery, view, download or re-use, instead of being stored in isolated silos after project completion [35].

\section{State of the Art}

Several recent publications have described methods and techniques that measure $\mathrm{CH}$ areas with the use of UAS. In [36] the use of quadcopters and methods for creating image mosaics, 3D point clouds and image models are described, in order to monitor natural and cultural resources. Also, a number of future directions in improving UAS technology are proposed. In $[37,38]$ UAS platforms and photogrammetric methodologies were used to analyze and map indigenous settlements in the Caribbean. In Zheng Sun and Yingying Zhang [39], drones and 3D modeling are used to survey Tibetan architectural heritage. The paper evaluates the accuracy of the UAV-SfM method for surveying a Tibetan stupa and illustrates how the results could be elaborated in a next-step analysis and used for management purposes.

Over the last decade, there have been some promising works regarding information systems for storing, searching and retrieving data acquired from UAS. More specifically, in [40] a server-based software tool is illustrated, supporting an automated workflow for raster data pre-processing, georeferencing, cataloging and dissemination in near real time. The ISO 19115 metadata standard by the International Organization for Standardization (ISO) was used for image documentation, recording both geometric and keyword metadata elements. Also, in [41], a similar tool is presented, emphasizing on the generation of precision metadata needed for geo-pointing at a particular target coordinate on the ground. Both studies are based on proprietary products and focus on near real-time provision of UAS-acquired images to ground stations. Each image is accompanied with a set of metadata elements that supports the functionality of the application domain.

\section{Materials and Methods}

In this section, we describe the SfM methodology applied to photographs captured from UAS for two $\mathrm{CH}$ areas in the coastal zone of Mytilene and Eresos cities. Also, we describe the development of a metadata cataloging system used for the organization and management of both acquired and produced geoinformation.

\subsection{Case Study Areas}

Ancient harbor installations constitute appropriate cases studies for a closer examination of the research topic presented in this manuscript. Both case studies are ancient harbors existing in Lesvos Island, Greece.

\subsubsection{The Ancient Harbor of Mytilene}

From the Archaic period, Mytilene had two harbors, the North and the South, which are still being used. The North harbor, known also as 'the Commercial', was fully established in the second half of the 4th century B.C. It was an artificial monumental structure with built outer breakwaters, in which a defense wall at the outer face and a quay at the inner face, were combined. In the coastal 
zone of the basin, at least one rectangular jetty was indicated. In direct contact with the seafront of the North harbor, the city's agora was created, as it turns out by four commercial stoae that have been partially excavated [42]. A section of the ancient basin was embanked due to the construction of the Lower Castle in the Post-Byzantine period. Furthermore, excavations at the modern coastal road (now called 'Naumachias Ellis') have brought to light the artificial quay of the ancient harbor.

\subsubsection{The Ancient Harbor of Eresos}

The city of Eresos, the birthplace of Sappho and Theophrastus, was founded on a hill, called 'Vigla' or 'Mastos', by the Aeolian settlers, who came from mainland Greece at the end of the second millennium B.C. Eresos' coastal zone is directly exposed to the south winds, so the construction of an artificial harbor at the east of the hill was required. The trapezoid acropolis hill had a protective defense wall (length 1 kilometer, area of 45 hectares) since the Archaic period (6th century B.C.), constructed with the so-called 'Lesbian masonry'. At the same period, the harbor was constructed at the south of the hill, with the same building system. Most likely it is one of the earlier examples of 'kleistos limen' (= enclosed harbor) in the Aegean Sea. The artificial harbor was sheltered to some extent by rocky islets, while at the north and north-west it was protected by the construction of an L-shaped breakwater, which runs from the coast to the islets.

The coastal infrastructures have been literally disappeared by the basin's partial embankment, while the modern fishing shelter distorted the original form of the ancient harbor. The landscape of the ancient city's coastal zone has recently further deteriorated by the recent construction of the coastal road (the early 1990s) and the natural and man-made embankment of the area at the west of the acropolis (where the modern touristic settlement is located). Ancient authors (Strabo 13.2.4; Athenaeus 3.1; Archestratos SH 135) wrote that the acropolis was surrounded by waves, describing in the best way the shift of the coastline.

\subsection{Unmanned Aerial Systems (UAS) Data Acquitition and Products}

SfM photogrammetry applied to photographs captured from UAV platforms is increasingly being utilized for a wide range of applications. SfM is a photogrammetric pipeline, which creates 3D visualizations from two-dimensional image sequences $[43,44]$. The methodology is one of the most effective methods in the computer vision field, consisting of a series of algorithms that detect common features in images and convert them into three-dimensional information. Initially, common features are detected in every image and then they are matched within the dataset [45]. The position of every point in 3D space is calculated, and a sparse point cloud is generated [46]. Subsequently, the sparse point cloud is thickened, and a dense point cloud is created. The last part of the methodology is the 3D model construction. A triangular mesh is created which describes the geometry of the constructed object or area accurately.

The UAS-SfM methodology followed three steps that are illustrated in the following figure (Figure 1).

The methodology used in this study enables the development of high-resolution orthophoto maps, accurate DSM and DTM, and finally very detailed 3D models of the study area [19-25].

The UAS used for both data acquisitions was a vertical take-off and landing (VTOL) configuration with capability to flight autonomously using pre-programmed flight paths. It consists of the airframe, the motors and the power system. The configuration used was a custom-made airborne system based on the S900 DJI hexacopter airframe. The UAS was capable of a 25-minute flight time with a payload of $1.5 \mathrm{~kg}$. S900-UAS geolocation information was recorded by a differential global positioning system connected to the autopilot. Furthermore, the configuration used lies in the Pixhawk autopilot system that is an open-source configuration [47,48]. The Sony A5100 24.3-megapixel used as survey camera capable of precise autofocusing in $0.06 \mathrm{sec}$ It was selected because of the lightweight $(0.224 \mathrm{~kg})$, manual functions and auto triggering capabilities through autopilot. The open access Mission Planner v1.25 
software used as a ground station for monitoring in real time the UAS telemetry and setup the flight missions [49].

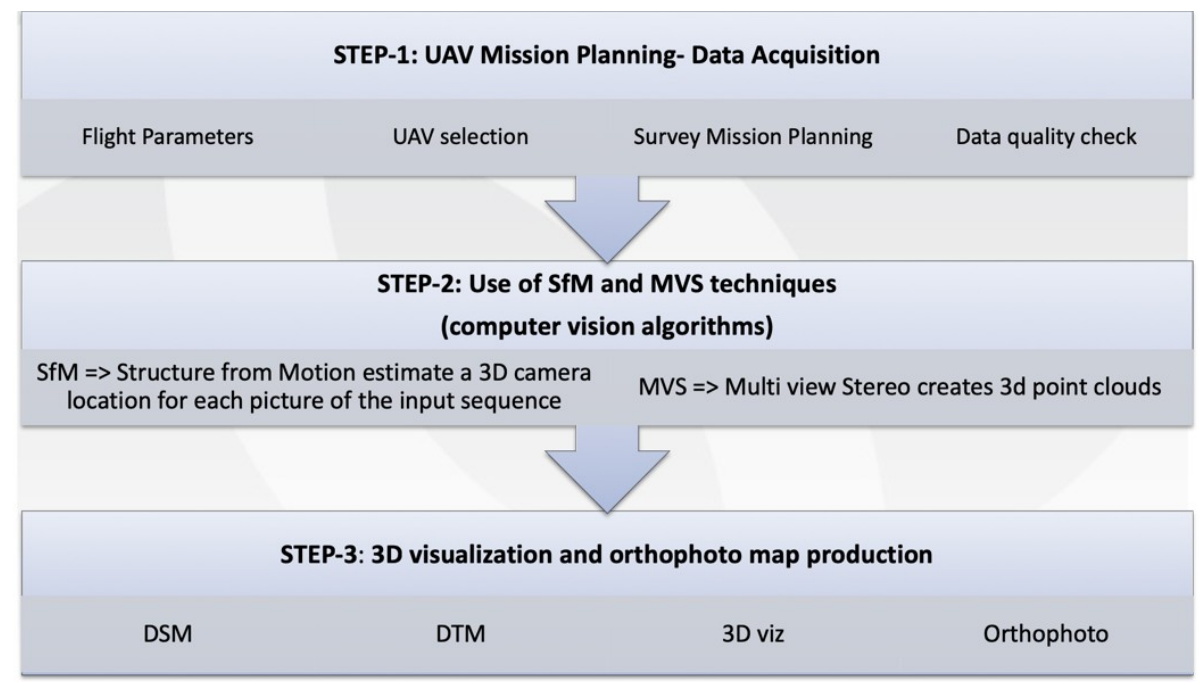

Figure 1. Unmanned Aerial Systems-Structure from Motion (UAS-SfM) methodology consisted of 3 steps.

Acquisitions acquired on 21 June 2017 for Eresos ancient harbor, and on the 21 October 2018 for Mytilene ancient harbor. Sea level for both dates extracted using the Kos island radar sensor of the sea level station monitoring facility and was measured for Eresos and Mytilene area $-10 \mathrm{~cm}$ and $10 \mathrm{~cm}$ respectively. All data acquisition flights were planned in such a way to cover the case study areas with an expected resolution of $2.05 \mathrm{~cm}$. Moreover, each acquisition planned to use the following flight parameters, overlap in-track $75 \%$ for Mytilene and $80 \%$ for Eresos survey when the side-lap was set to $75 \%$ in both cases. The UAV was flying at a height of $100 \mathrm{~m}$ above the sea level (absolute height) having a velocity of $5 \mathrm{~m} / \mathrm{s}$ in both study areas, thus the sensor was setup for capturing a photograph every 3.28 seconds with nadir direction. After a quality control inspection, the majority of the images were selected for further processing. In the following table (Table 1) the information for data acquisition is depicted.

Table 1. UAS survey mission details for Mytilene and Eresos ancient harbors.

\begin{tabular}{cccccccc}
\hline Case Study & $\begin{array}{c}\text { No } \\
\text { Images }\end{array}$ & $\begin{array}{c}\text { Flight } \\
\text { Time } \\
\text { (min:s) }\end{array}$ & $\begin{array}{c}\text { Fight } \\
\text { Height } \\
\mathbf{( m )}\end{array}$ & $\begin{array}{c}\text { Overlap } \\
\mathbf{( \% )}\end{array}$ & $\begin{array}{c}\text { Side Lap } \\
\mathbf{( \% )}\end{array}$ & $\begin{array}{c}\text { Area } \\
(\mathbf{s q m})\end{array}$ & $\begin{array}{c}\text { Ground } \\
\text { Sample } \\
\text { Distance (cm) }\end{array}$ \\
\hline $\begin{array}{c}\text { Mytilene } \\
\text { ancient harbor }\end{array}$ & 408 & $18: 33$ & 100 & 75 & 75 & 84,127 & 2 \\
\hline $\begin{array}{c}\text { Eresos ancient } \\
\text { harbor }\end{array}$ & 172 & $14: 18$ & 100 & 80 & 75 & 106,214 & 2 \\
\hline
\end{tabular}

The obtained ground resolution of the images acquired from the UAS was $2 \mathrm{~cm} /$ pixel and each image had a footprint 123.7 to 82.1 meters. Prior to the survey missions, geo-referenced mobile targets were used as ground control points (GCP) having dimensions of $40 \times 40 \mathrm{~cm}$ and were designed in a black and white pattern. These targets were well distributed and homogeneous only in the coastal zone of the study area as the old remains were submerged in the sea due to the sea surface level. The use of GCPs in both surveys had as a result a root mean squared error (RMSE) of $1.87(\mathrm{~cm})$ and $1.56(\mathrm{~cm})$ in Eresos and Mytilene old harbors derivatives respectively. The accuracy achieved met the requirements of the authors for creating highly detailed orthophoto maps.

For the realization of this study, the Agisoft Photoscan 1.4.1 [50] was used, because it automates the SfM pipeline in a user-friendly interface with a concrete workflow. In particular, Photoscan automates 
the detection of feature points in each image and match them with the total of images captured from the UAS. These matches produced a sparse point cloud as the basis for the generation of the scene geometry as represented by a dense point cloud [44,51-53]. Finally, the dense 3D point cloud and the total of images were to create (i) a 3D mesh of the area ii) high-resolution orthophotos, (iii) DSM as well as (iv) DTM. All derivatives had no displacements and perfectly match when superimposed for validation to satellite imagery such us ESRI base maps, Google Earth imagery and Hellenic Cadastre latest orthophotos. The details of the derivatives produced are illustrated in the following table (Table 2).

Table 2. Additional information for the UAS-SfM derivatives.

\begin{tabular}{ccccccc}
\hline Case Study & No Images & $\begin{array}{c}\text { Dense Point } \\
\text { Cloud } \\
\text { (point) }\end{array}$ & $\begin{array}{c}\text { Image Foot } \\
\text { Print } \\
\text { (m) }\end{array}$ & $\begin{array}{c}\text { Mesh } \\
\text { (faces) }\end{array}$ & $\begin{array}{c}\text { DSM } \\
\text { Resolution } \\
\text { (cm) }\end{array}$ & $\begin{array}{c}\text { Orthophoto } \\
\text { Resolution } \\
\text { (cm/pixel) }\end{array}$ \\
\hline $\begin{array}{c}\text { Mytilene } \\
\text { ancient } \\
\text { Harbor }\end{array}$ & 408 & $70,049,007$ & $123.7 \times 82.1$ & $13,974,322$ & 3.92 & 2.5 \\
\hline $\begin{array}{c}\text { Eresos } \\
\text { ancient } \\
\text { Harbor }\end{array}$ & 172 & $85,268,778$ & $123.7 \times 82.1$ & $12,053,754$ & 3.92 & 2.5 \\
\hline
\end{tabular}

\subsection{The Development of the Metadata Cataloging System}

In order to facilitate on-line searching and retrieving operations for all data items acquired or produced during $\mathrm{CH}$ areas' representation projects, a specific metadata cataloging system was developed, based on the INSPIRE metadata regulation [36]. INSPIRE [37] is the Directive of the European Union for the creation of a spatial data infrastructure supporting environmental policies and policies or activities which may have an impact on the environment. The decision for the directive adoption by our system was made in order to be compatible with other systems for spatial information discovery and sharing. In the following two sub-sections, the requirement analysis and implementation steps are described in brief, while the functionality of the system is presented in the Results section.

\subsubsection{Requirements Analysis}

Bibliographic research, as well as research through interviews with members of the work team, was carried out. The purpose of the above was to analyze and document the process of taking aerial photographs using drones and the processing of those photographs for the production of derivative products. In this way, we were able to check whether the INSPIRE metadata model covers documentation needs and to finalize the additional metadata elements.

The two key concepts that were chosen to be added were those of "project" and "mission". The project concerns a specific $\mathrm{CH}$ area, in which a series of UAS flights (missions) are planned and carried out. Aerial photographs are taken during missions. In addition, to facilitate and simplify the metadata insertion process and to enhance the usability of the system, we kept the number of the new metadata elements to the minimum and we defined default values and auto-fill fields for many of them.

Regarding the choice of the software platform for the implementation of the system, the requirements were to be free and open-source, as well as not to require a very high load of computer programming.

The result of the requirement analysis was the finalization of a metadata profile, which is an extension of the INSPIRE metadata regulation. Table 3 below contains all new elements (other than ones introduced by INSPIRE), which were introduced to meet the requirements. 
Table 3. Additional metadata elements extending the INSPIRE regulation.

\begin{tabular}{|c|c|c|c|}
\hline No. & Element Category & Metadata Element ${ }^{1}$ & Description \\
\hline 1 & Project & Title & $\begin{array}{l}\text { A single title to the overall project undertaken, } \\
\text { consisting of several missions. Usually the } \\
\text { toponym of the cultural heritage area }\end{array}$ \\
\hline 2 & UAS Mission & Title & The title of the mission. \\
\hline 3 & & Identifier & $\begin{array}{l}\text { A code that is characteristic of the particular } \\
\text { mission, which can be used during the search } \\
\text { process }\end{array}$ \\
\hline 4 & & Abstract & A summary of the mission. \\
\hline 5 & & Operator's Name & The name of the UAS operator. \\
\hline 6 & & Operator's E-mail & The UAS operator's e-mail address. \\
\hline 7 & & Data Type & $\begin{array}{c}\text { The type of the documented data file. It can } \\
\text { be selected from a drop-down menu (Photo, } \\
\text { Sparse, Dense, Coastline, DSM, Orthophoto } \\
\text { or Other). }\end{array}$ \\
\hline 8 & & File Location & The path/locator of the file. \\
\hline 9 & & Data Date & The reference date of the data file. \\
\hline 10 & & Date Type & $\begin{array}{l}\text { The type of the reference date. date. It can be } \\
\text { selected from a drop-down menu (Creation, } \\
\text { Issue, Revision). }\end{array}$ \\
\hline 11 & & Mission's Area & The flight area of the mission. \\
\hline 12 & & Flight's Altitude & The flight's altitude. \\
\hline 13 & & Camera's Model & The model of the camera. \\
\hline
\end{tabular}

\subsubsection{System Implementation}

The ESRI Geoportal Server-Open Source Metadata Management (Geoportal Server for short) was selected as the most appropriate software platform for the implementation of the system. This software complied with most of the requirements and yielded the desired results.

Geoportal Server supports some out-of-the-box geospatial metadata standards, including INSPIRE. To extend it with the additional metadata elements described above, certain code files were modified, mainly in HTML, XML and XSL/XSLT mark-up languages. More specifically, a copy of the INSPIRE folder was made firstly into the Geoportal Template folder (which contains all metadata profiles). The "inspire-template.xml" file was edited in order to modify existing or define new metadata elements; the "inspire-definition.xml" file was edited in order to define the graphical representation of the metadata elements; and the "inspire-indexables.xml" file was edited in order the new metadata elements to be available for searching operations. The technical details of the implementation are outside the scope of this article.

The system is hosted by a local server within the network of the University of the Aegean, where all the metadata records are stored. It is available at the URL http://geo-aegean.aegean.gr:8091/geoportal and can be used by any web browser. The files acquired or produced during the UAS-SfM methodology are also stored at (different) local servers, at appropriate formats (e.g., geotiff format for DSM files and orthophoto maps).

1 Metadata elements in bold are mandatory. 


\section{Results}

\subsection{Unmanned Aerial Systems-Structure from Motion (UAS-SfM) Products}

The UAV-SfM pipeline was performed for both study areas, Mytilene and Eresos ancient harbors, thus, resulting in a sparse point cloud as a basis of the creation of the scene geometry represented as dense point cloud [44,51-53]. The dense 3D point cloud and the total of images used were meshed to: (i) a 3D mesh of the geometry, (ii) high-resolution orthophotos, and (iii) DSM. All the produced geoinformation was geo-referenced to WGS84/UTM34N. The dense point clouds produced for Mytilene and Eresos ancient harbors (Figures 2 and 3) consisted of 453 point $/ \mathrm{m}^{2}$ and 423 point $/ \mathrm{m}^{2}$, respectively. The produced orthophoto pixel resolution was $2.05 \mathrm{~cm} /$ pixel for both Mytilene and Eresos old harbors. Furthermore, the DSM pixel resolution produced for the Mytilene ancient harbor was $4.35 \mathrm{~cm} / \mathrm{pixel}$, while the DSM pixel resolution for the Eresos harbor survey was $4.68 \mathrm{~cm} /$ pixel.

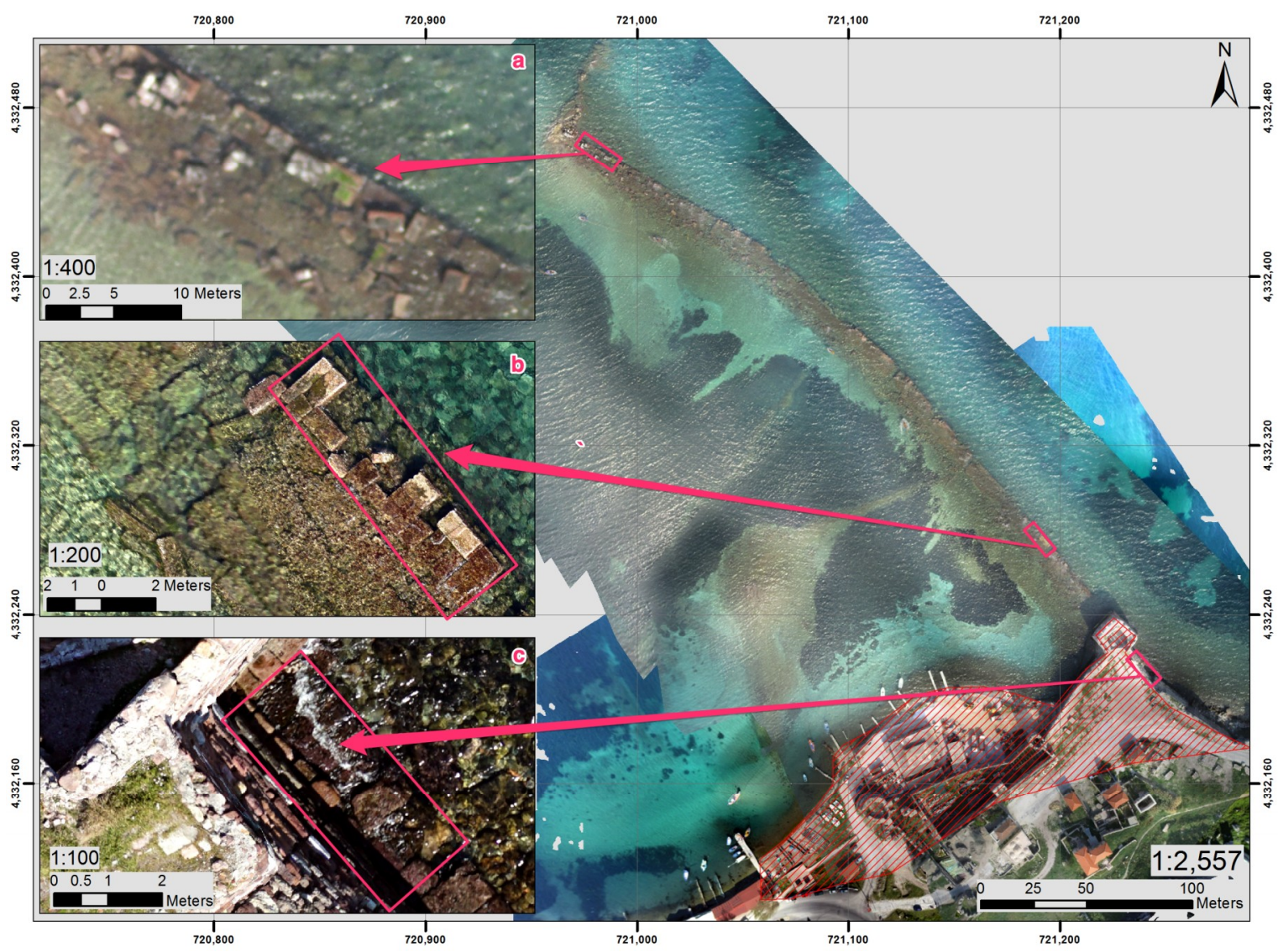

Figure 2. The orthophoto map depicting Mytilene's ancient harbor. (a) is depicting in detail a part of the two outer ashlar faces that are filled with rubble; (b) portrays one of the transverse openings 'channels', and ashlar blocks that are laid in horizontal courses at the side; (c) depicts the part of the original harbor's basin that was covered by the North East Tower of the Ottoman Lower Castle; (d) The orthophoto map depicting the southeastern breakwater and part of the Mytilene's ancient harbor basin that was covered by the Ottoman Lower Castle $(\rho \varepsilon \delta)$. 


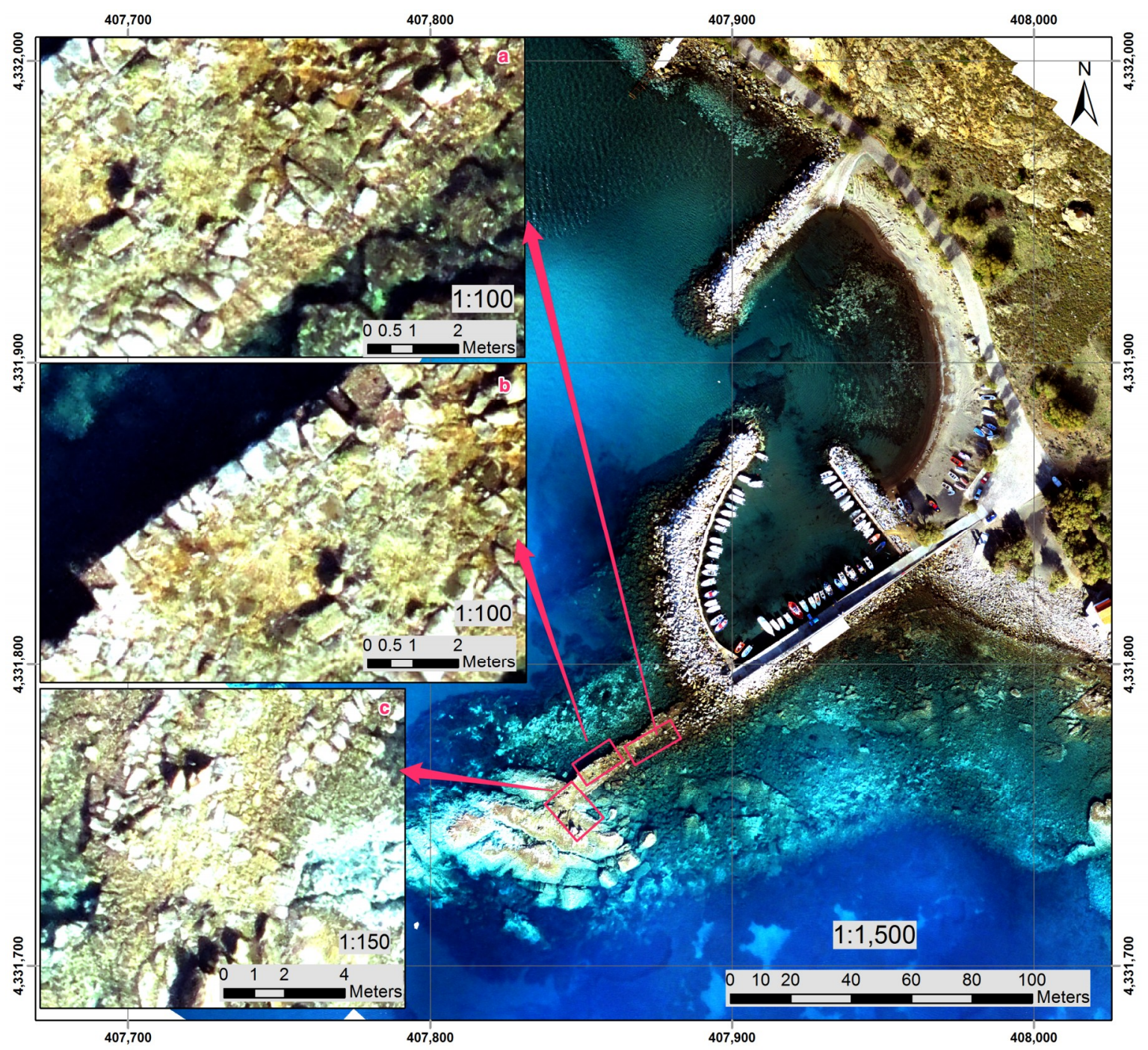

Figure 3. The orthophoto produced for the Eresos ancient harbor: (a) is depicting a section of the harbor that is partially destroyed when (b) portrays a section that is preserved in good condition; (c) visualizes the relation of the built breakwater with the roughly shaped/modulated volcanic reefs.

\subsection{Findings from the Orthophoto Maps}

\subsubsection{The Ancient Harbor of Mytilene}

For the North harbor, in particular, the orthophoto maps produced revealed that an extended area of $8028 \mathrm{~m}^{2}$ of the original harbor's basin was covered by the Ottoman Lower Castle (red area in Figure 2) and that the modern road of Naumachias Ellis Street changed the ancient coastline for about 35 to $40 \mathrm{~m}$ [54]. In addition, for the very first time the real dimensions of the southeastern breakwater together with the structural details were measured. More specifically, the orthophotos created revealed detailed information to the archaeologists for critical parts of the ancient building stock such as the transverse openings 'channels', ashlar blocks that are laid in horizontal courses at the sides, and the two outer ashlar faces that are filled with rubble (Figure 2).

\subsubsection{The Ancient Harbor of Eresos}

The orthophoto maps produced made it possible to accurately measure the dimensions of the harbor installations; the remaining breakwater has an average width of $7.3 \mathrm{~m}$. , a maximum length of $140 \mathrm{~m}$. and a maximum preserved height of $2.5 \mathrm{~m}$. The structure is measured from the rocky edge of the 
seashore, from which it projected. The ancient harbor now is beneath the modern fishing shelter basin which totally covered the ancient breakwater for $85.5 \mathrm{~m}$ [7]. In addition, the orthophoto helped the scholars to understand the real condition of the built structure as far as the old harbor preservation was concerned. In particular which sections are preserved in good condition in full width (Figure $3 b$ ) and which are partially destroyed (Figure 3a) by a series of factors; man-made disasters through centuries, forces of nature (earthquakes, strong wave action).

Moreover, the archaeologists for the very first time had access to high-resolution pictures and orthophotos of the harbors, thus they were able to examine in more detail the relation of the built breakwater with the roughly shaped/ modulated volcanic reefs (Figure 3c).

\subsection{Cataloging System Functionality}

Our metadata cataloging system was used for the documentation of all data acquired or produced during the presented case studies. More specifically, 586 files were documented (580 photographs, 2 point-cloud files, 2 DSM files and 2 orthophoto maps).

The main operations of the system are three-fold: (a) metadata records creation (insertion), (b) verification of validity and completeness of metadata records, and (c) metadata searching. The last one may be performed by anonymous users, while the former two require appropriate authentication. Figures 4 and 5 present the metadata editor form (upper and lower part, respectively). The "Project" and "Mission" sections of the form contain the new metadata elements, while the other ones contain the normal elements of the INSPIRE regulation. 


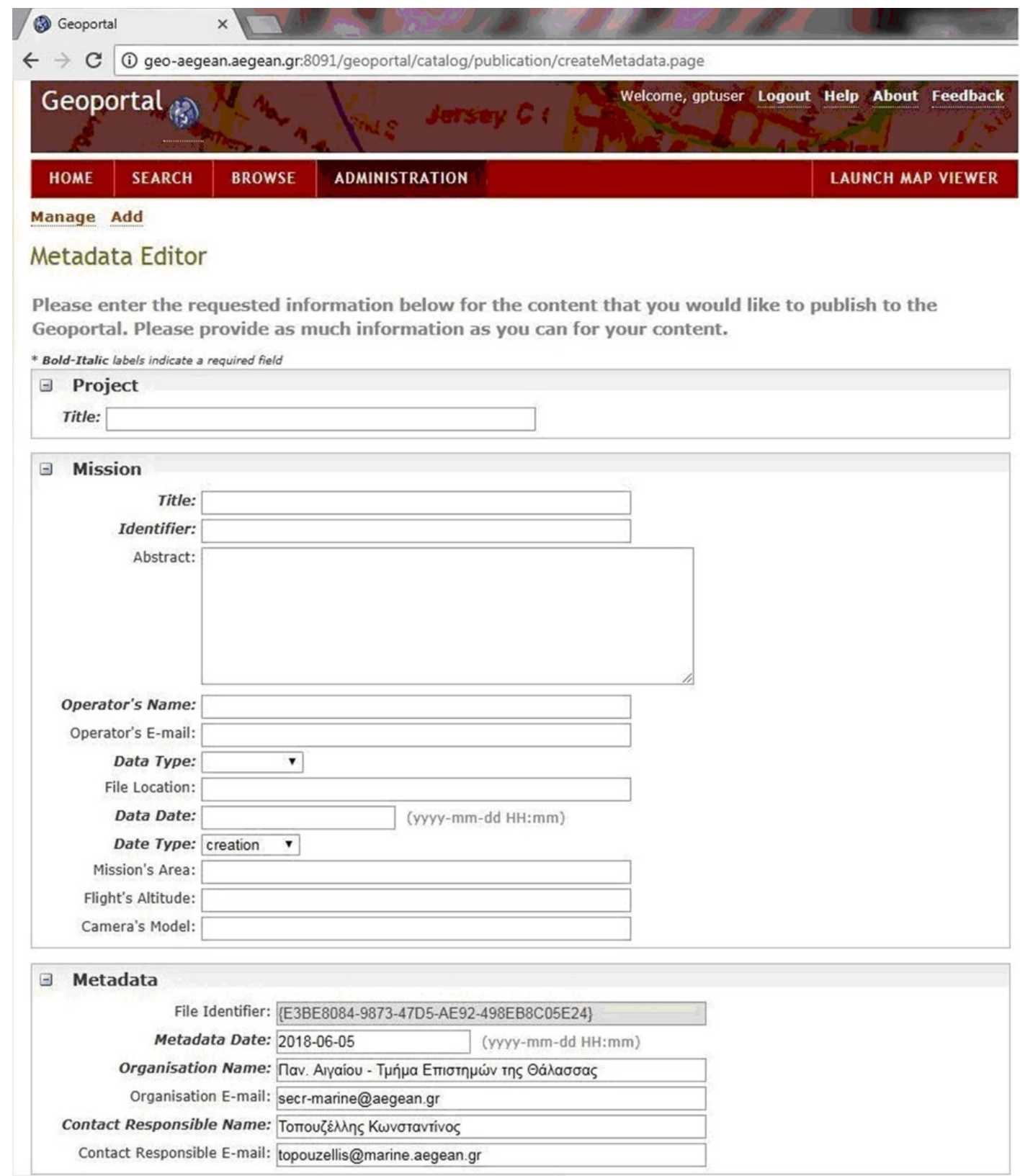

Figure 4. Metadata editor (upper part). 


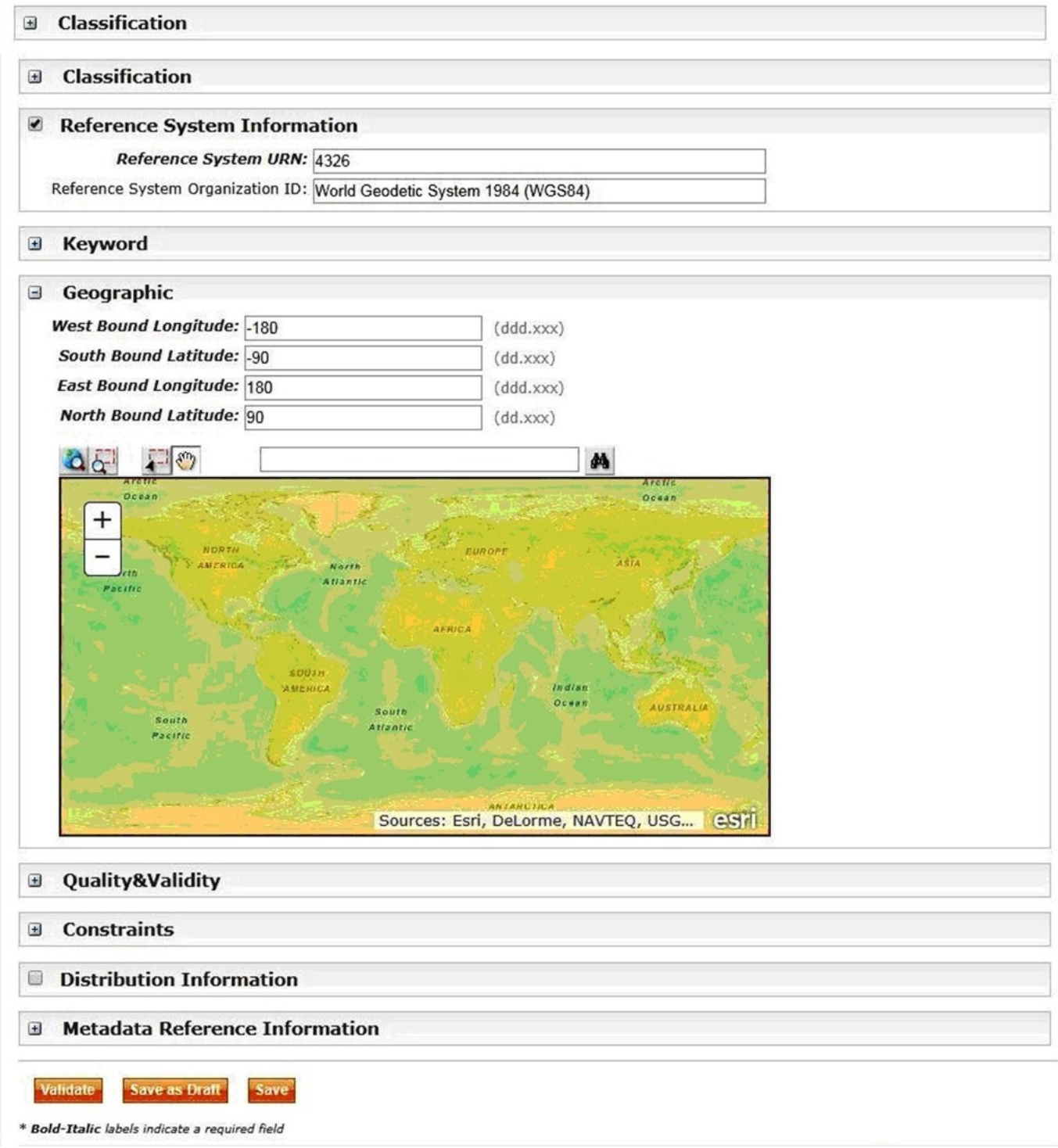

Figure 5. Metadata editor (lower part).

After the insertion of a metadata record, its validity and completeness are checked by the system: all mandatory elements should be filled-in and all values should be valid against their domain. Successful verification is a prerequisite for the metadata record to be stored. At this point, it should be clarified that whenever a record is stored successfully, it is marked as posted, but is not available during the searching operation. It first has to be approved by an authorized user. This ensures the overall validity of the metadata, which cannot be controlled in an automated manner.

Metadata searching operations are provided by the form of Figure 6. Two operations are available: (a) searching by keywords, and (b) searching by advanced criteria. 


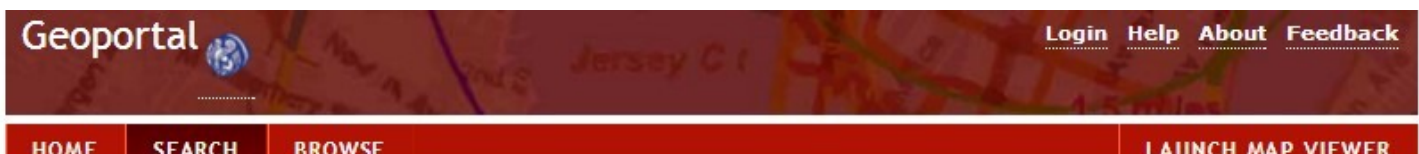

Search

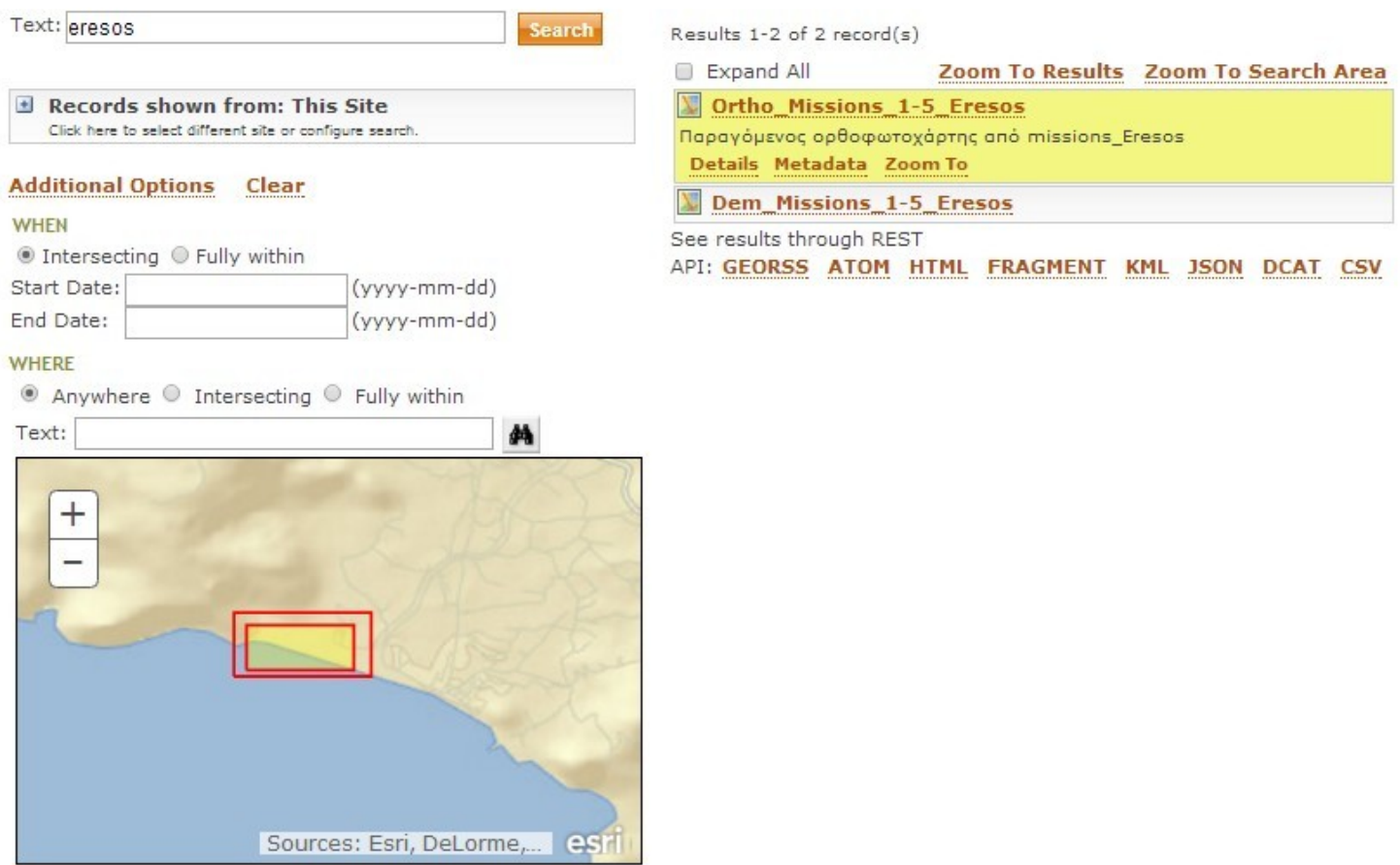

This Geoportal was built using the Geoportal Server. Please read the Disclaimer and Privacy or Contact Us.

Figure 6. Searching form.

A keyword search can be done by completing keywords in the "Text" field and pressing the "Search" button. All metadata records containing these words in the "Abstract" element are displayed on the right side of the form. If a keyword is preceded by the asterisk symbol $\left({ }^{*}\right)$, then the results include the records containing the keyword in any element. At the lower left corner of the form, a map is displayed showing in red the bounding boxes of the records matching the search criteria.

Advanced search criteria may be entered for other fields of the form or by selecting the "Additional options". For a geographical search, the interactive map of the form may be used for the desired area designation. In this case, the user can choose whether the records to be selected should be either intersecting or fully within this area. Once the result set is displayed, additional command options are activated (Details, Metadata, Zoom To). With the "details" option, the full content of the metadata record is displayed (Figure 7). The "Metadata" option produces an XML representation of the record, while the "Zoom To "option limits the map area extent of the selected record. 


\section{Discussion}

As previously stated in $[25,55]$, the UAV-SfM derived products enable change detection, the discovery of new hidden structures, pattern analysis and documentation of coastal zones, in various spatial and temporal scales. The miniaturization of sensors, the increase in the flight capabilities and the agility of a UAV fulfill researchers need in spatial data acquisition for $\mathrm{CH}$ mapping [13,56-58]. UAS can be seen as a new tool for mapping $\mathrm{CH}$ areas in the coastal zone. Furthermore, the high level of automation, the ease of deployment, the ease of survey repeatability, and the low running costs of UAVs allow frequent missions that provide spatial datasets with a resolution of less than $5 \mathrm{~cm}$ and a high temporal repetition due to the ease of survey deployment $[12,59,60]$. In previous studies geo-referenced orthophotos and DSMs are used to measure and depict the morphology of $\mathrm{CH}$ areas in 2D and 3D, allowing archaeologist to assess the condition of the ancient building stock, especially after extreme environmental phenomena $[9,25,61]$, e.g., heavy rain, earthquake etc.

The application of the UAV-SfM pipeline for the two ancient harbors of Lesvos Island offers to archeologists and local authorities high-resolution geoinformation (orthophotos, DSM, etc.) that can be used to support their objective. Furthermore, it provides a valuable snapshot of the current state of the harbor building stock in high-resolution visualizations. The UAS-SfM methodology derivatives are valuable tools for rapid mapping of the harbor installations and may be used to automate the detection procedures, where conventional mapping techniques are difficult and time-consuming. It is worth noting that for the Mytilene and Eresos ancient harbors there were not detailed topographical maps previously available for the archaeologists and scientists to study these installations.

During the applied surveying and representation procedures, a large number of different files were produced by various users in different periods of time, requiring considerable amounts of time for cataloging and disk space for storage. To overcome problems often encountered in such cases (like storing data in silos without discovery mechanisms, duplication of files, undefined version control, lack of the overall UAS flight history for an area, or making unnecessary duplicate flights), all files were documented in our metadata cataloging system. The metadata profile used, extends the INSPIRE geospatial metadata regulation with elements about $\mathrm{CH}$ mapping projects and their accompanying UAS flights, in order to be convenient to end-users. Keeping files in different local servers and the metadata records in another, offer flexibility in space utilization and access rights management, and uniformity in cataloguing and searching operations.

\section{Conclusions}

Contemporary research activities of the spatial sciences require flexibility in terms of data re-usability, mainly due to limitation of funds and resources [62]. In this work, we have shown that the utilization of UAS for capturing rapidly, with agility and at low-cost aerial photographs of high resolution and accuracy, in conjunction with the SfM and MVS techniques, provide quality 2D visualizations of $\mathrm{CH}$ areas for archeologists and local authorities. The quality of the orthophoto maps produced from UAV-SfM methodology enables the identification and measurement of hidden details in the archaeological sites over the total extent of the mapped area. Thus, this can help to measure details of ancient structures that were previously vague without the need to visit them, or to purchase expensive high-resolution satellite imagery. Furthermore, the detailed geoinformation produced from the data acquired using UAS can provide the researchers with valuable information for the current state of the harbor installations building stock. Moreover, the derived data products enable detailed 2D and 3D analysis thus change detection or landscape development analysis for archeological areas is possible. The high resolution and precision of the derived orthophoto maps and visualizations following UAS-SfM process cannot be achieved from satellite datasets.

In addition, in this study, we have presented a web-based information system for the documentation of all data (acquired or produced) with metadata elements customized for the UAS-SfM pipeline. The system supports searching operations with keyword-based or geographic criteria, enhancing data discovery and re-usability. The adaption and extension of the INSPIRE spatial metadata regulation of the 
European Union enable interoperability with other metadata catalogs through standard geographical web services and harvesting functionality. Keeping surveying and representation procedures for $\mathrm{CH}$ areas at low-cost makes it possible to carry them out more frequently, with obvious positive results in destruction prevention and preservation/protection decision-making. It is concluded that the UAV-based data acquisition provides a valuable alternative for mapping and monitoring of coastal zones with archaeological monuments and sites. Several important beach characteristics, as well as archaeological information, can be revealed using high-resolution orthophoto maps in contrast to high-resolution satellite images.

Potential future work includes the expansion of the study to other coastal $\mathrm{CH}$ areas of Lesvos Island, supporting authorities in the direction of the establishment of an overall protection policy. Also, a number of improvements of the cataloging system are planned, mainly in the field of searching functionality and flexible user privileges support. More UAS data acquisition surveys in different temporal periods should be implemented to monitor spatiotemporal changes in the $\mathrm{CH}$ areas to identify affected areas. Having detailed geoinformation in different time periods can reveal the dynamics of erosion and other dangers affecting cultural heritage. As more flights will be done and more data are created for the $\mathrm{CH}$ areas of interest, the archeological and cultural authorities will have a valuable metadata tool to define and prioritize areas that are in more immediate danger and to preserve them accordingly, as well as to manage coastal areas of cultural heritage.

Author Contributions: Conceptualization, A.P., K.T., M.V. and D.K.; Methodology, A.P., K.T., M.V. and D.K.; Software, M.V., M.C., V.K.; Resources Y.K.; Writing-Original Draft Preparation, A.P., K.T., M.V., Y.K. and D.K.; Writing-Review \& Editing, A.P., K.T., M.V., Y.K. and D.K.; Visualization, A.P.; Supervision M.V.

Funding: This research was partially funded by Greek State Scholarship Foundation (I.K.Y.) within the "Strengthening Post-Doctoral Research" Scholarship Programs grant number [MIS: 5001552].

Conflicts of Interest: The authors declare no conflict of interest.

\section{References}

1. Ziegler, V. Anatomy of an Urban Design Project: Bordeaux New Garonne Riverbank. In New Faces of Harbour Cities; Dündar, S..G., Karataş, N., Erdin, H.E., Lorens, P., Dundar, S.G., Karatas, N., Eds.; Cambridge Scholars Publishing: Newcastle, UK, 2014; pp. 103-119.

2. Franco, L. Ancient Mediterranean harbours: A heritage to preserve. Ocean Coast. Manag. 1996, 30, $115-151$. [CrossRef]

3. Blackman, D.J. Ancient harbours in the Mediterranean. Part 2. Int. J. Naut. Archaeol. 1982, 11, $185-211$. [CrossRef]

4. Blackman, D.J. Ancient harbours in the Mediterranean. Part 1. Int. J. Naut. Archaeol. 1982, 11, 79-104.

5. Evelpidou, N.; Karkani, A. Archaeology and Sea-Level Change Encyclopedia of Coastal Science. In Encyclopedia of Coastal Science; Finkl, C.W., Makowski, C., Eds.; Springer International Publishing AG: Basel, Switzerland, 2018; pp. 1-7.

6. Marriner, N.; Morhange, C. Geoscience of ancient Mediterranean harbours. Earth-Sci. Rev. 2007, 80, 137-194. [CrossRef]

7. Theodoulou, T. Recording the harbour network of ancient Lesbos (2008-2009). In Byzas 19. Proceedings of the Harbors and Harbor Cities in the Eastern Mediterranean from Antiquity to the Byzantine Period: Recent Discoveries and Current Approaches; Schmidts, S., Ladstätter, F., Pirson, T., Eds.; Ege Yayinlari, Publisher: Instanbul, Turkey, 2014; pp. 493-508.

8. Agapiou, A.; Lysandrou, V.; Alexakis, D.D.; Themistocleous, K.; Cuca, B.; Argyriou, A.; Sarris, A.; Hadjimitsis, D.G. Cultural heritage management and monitoring using remote sensing data and GIS: The case study of Paphos area, Cyprus. Comput. Environ. Urban Syst. 2015, 54, 230-239. [CrossRef]

9. Papakonstantinou, A.; Doukari, M.; Stamatis, P.; Topouzelis, K. Coastal Management using UAS and High-Resolution Satellite Images for Touristic Areas. Int. J. Appl. Geospat. Res. 2019, 10, 54-72. [CrossRef]

10. Pajares, G. Overview and Current Status of Remote Sensing Applications Based on Unmanned Aerial Vehicles (UAVs). Photogramm. Eng. Remote Sens. 2015, 81, 281-330. [CrossRef] 
11. Yastikli, N.; Bagci, I.; Beser, C. The Processing of Image Data Collected by Light UAV Systems for GIS Data Capture and Updating. ISPRS Int. Arch. Photogramm. Remote Sens. Spat. Inf. Sci. 2013, XL-7/W2, 267-270. [CrossRef]

12. Gonçalves, J.A.A.; Henriques, R. UAV photogrammetry for topographic monitoring of coastal areas. ISPRS J. Photogramm. Remote Sens. 2015, 104, 101-111. [CrossRef]

13. Brunier, G.; Fleury, J.; Anthony, E.J.; Gardel, A.; Dussouillez, P. Close-range airborne Structure-from-Motion Photogrammetry for high-resolution beach morphometric surveys: Examples from an embayed rotating beach. Geomorphology 2016, 261, 76-88. [CrossRef]

14. Topouzelis, K.; Papakonstantinou, A.; Garaba, S.P. Detection of floating plastics from satellite and unmanned aerial systems (Plastic Litter Project 2018). Int. J. Appl. Earth Obs. Geoinf. 2019, 79, 175-183. [CrossRef]

15. Zhang, C.; Kovacs, J.M. The application of small unmanned aerial systems for precision agriculture: A review. Precis. Agric. 2012, 13, 693-712.

16. Solbo, S.; Storvold, R. Mapping Svalbard Glaciers with the Cryowing Uas. ISPRS Int. Arch. Photogramm. Remote Sens. Spat. Inf. Sci. 2013, XL, 4-6. [CrossRef]

17. Chahl, J. Unmanned Aerial Systems (UAS) Research Opportunities. Aerospace 2015, 2, 189. [CrossRef]

18. Christie, K.S.; Gilbert, S.L.; Brown, C.L.; Hatfield, M.; Hanson, L. Unmanned aircraft systems in wildlife research: Current and future applications of a transformative technology. Front. Ecol. Environ. 2016, 14, 241-251. [CrossRef]

19. Cook, K.L. An evaluation of the effectiveness of low-cost UAVs and structure from motion for geomorphic change detection. Geomorphology 2017, 278, 195-208. [CrossRef]

20. Doukari, M.; Papakonstantinou, A.; Topouzelis, K. The integration of UAS and Structure for Motion pipeline for High- Resolution 3D visualization of beach zone topography. In Proceedings of the ISISA Islands of the World XIV Conference 2016, Mytilene, Greece, 23-27 May 2016; p. 1.

21. Eltner, A.; Baumgart, P.; Maas, H.G.; Faust, D. Multi-temporal UAV data for automatic measurement of rill and interrill erosion on loess soil. Earth Surf. Process. Landf. 2015, 40, 741-755. [CrossRef]

22. Mancini, F.; Dubbini, M.; Gattelli, M.; Stecchi, F.; Fabbri, S.; Gabbianelli, G. Using Unmanned Aerial Vehicles (UAV) for High-Resolution Reconstruction of Topography: The Structure from Motion Approach on Coastal Environments. Remote Sens. 2013, 5, 6880-6898. [CrossRef]

23. Papakonstantinou, A.; Doukari, M.; Topouzelis, K. UAS spatial data acquisition for High-Resolution 3D visualization of coastal topography. In Proceedings of the 11th 3D Geoinfo Conference, Athens, Greece, 20-21 October 2016; pp. 2-3.

24. Tonkin, T.N.; Midgley, N.G.; Graham, D.J.; Labadz, J.C. The potential of small unmanned aircraft systems and structure-from-motion for topographic surveys: A test of emerging integrated approaches at Cwm Idwal, North Wales. Geomorphology 2014, 226, 35-43. [CrossRef]

25. Papakonstantinou, A.; Topouzelis, K.; Pavlogeorgatos, G. Coastline Zones Identification and 3D Coastal Mapping Using UAV Spatial Data. ISPRS Int. J. Geo-Inf. 2016, 5, 75. [CrossRef]

26. Papakonstantinou, A.; Topouzelis, K.; Doukari, M. UAS close range remote sensing for mapping coastal environments. In Proceedings of the Fifth International Conference on Remote Sensing and Geoinformation of the Environment (RSCy2017), Paphos, Cyprus, 20-23 March 2017; Papadavid, G., Hadjimitsis, D.G., Michaelides, S., Ambrosia, V., Themistocleous, K., Schreier, G., Eds.; SPIE: Mytilini, Greece, 2017; Volume 10444 , p. 35.

27. Topouzelis, K.; Papakonstantinou, A.; Pavlogeorgatos, G. Coastline change detection using UAV, Remote Sensing, GIS and 3D reconstruction. In Proceedings of the 5th International Conference on Environmental Management, Engineering, Planning and Economics (CEMEPE) and SECOTOX Conference, Mykonos, Greece, 14-18 June 2015.

28. Johnson, P.; Ricker, B.; Harrison, S. Volunteered Drone Imagery: Challenges and constraints to the development of an open shared image repository. In Proceedings of the Proceedings of the 50th Hawaii International Conference on System Sciences (2017), Hilton Waikoloa Village, HI, USA, 4-7 January 2017.

29. Even, A.; Shankaranarayanan, G.; Watts, S. Enhancing decision making with process metadata: Theoretical framework, research tool, and exploratory examination. In Proceedings of the Annual Hawaii International Conference on System Sciences, Kauia, HI, USA, 4-7 January 2006.

30. Fisher, C.W.; Chengalur-Smith, I.S.; Ballou, D.P. The impact of experience and time on the use of data quality information in decision making. Inf. Syst. Res. 2003, 14, 170-188. [CrossRef] 
31. Moura, A.M.D.C.; Pereira, G.D.C.; Campos, M.L.M. A metadata approach to manage and organize electronic documents and collections on the web. J. Braz. Comput. Soc. 2002, 8, 16-31. [CrossRef]

32. Nogueras-Iso, J.; Zarazaga-Soria, F.J.; Muro-Medrano, P.R. Geographic Information Metadata for Spatial Data Infrastructures: Resources, Interoperability and Information Retrieval; Springer: Berlin/Heidelberg, Germany, 2005; ISBN 3540244646.

33. European Parliament and the Council of the European Union Commission Regulation (EC) No 1205/2008 of 3 December 2008 Implementing Directive 2007/2/EC as regards metadata. Off. J. Eur. Union 2008, 326, 12-30.

34. European Parliament and the Council of the European Union Directive 2007/2/EC of the European Parliament and of the Council of 14 March 2007 establishing an Infrastructure for Spatial Information in the European Community (INSPIRE). Off. J. Eur. Union 2007, L 108, 1-14.

35. Mckeague, P.; Corns, A.; Shaw, R.; Programme, T.D. Developing a Spatial Data Infrastructure for Archaeological and Built Heritage. Int. J. Spat. Data Infrastruct. Res. 2012, 7, 38-65.

36. Madden, M.; Jordan, T.; Cotten, D.; Hare, N.; Pascua, A.; Bernardes, S. The future of Unmanned Aerial Systems (UAS) for monitoring natural and culture resources. In Proceedings of the 55th Photogrammetric Week, Stuttgart, Germany, 7-11 September 2015.

37. Sonnemann, T.F.; Hung, J.U.; Hofman, C.L. Mapping indigenous settlement topography in the Caribbean using drones. Remote Sens. 2016, 8, 791. [CrossRef]

38. Sonnemann, T.F.; Malatesta, E.H.; Hofman, C.L. Applying UAS Photogrammetry to Analyze Spatial Patterns of Indigenous Settlement Sites in the Northern Dominican Republic. In Digital Methods and Remote Sensing in Archaeology; Springer: Cham, Switzerland, 2016.

39. Sun, Z.; Zhang, Y. Using drones and 3D modeling to survey Tibetan architectural heritage: A case study with the multi-door stupa. Sustainability 2018, 10, 2259. [CrossRef]

40. Runkel, I. Processing, cataloguing and distribution of UAS images in near real time. ISPRS Int. Arch. Photogramm. Remote Sens. Spat. Inf. Sci. 2013, XL-1/W2, 339-342. [CrossRef]

41. Brown, A.; Bockius, B.; Wetlesen, D.; Dalrymple, J.; Corporation, N. Near Real-Time Geo-Referenced UAV Imagery Collection and Web-Based Processing on a Server for Targeting and Mapping. In Proceedings of the ION GNSS 2008, Savannah, GA, USA, 16-19 September 2008.

42. Kourtzellis, Y.; Theotokis, T. Harbors and maritime routes in ancient Lesvos (in Greek). In Lesbian Calendar 2011. Letters, Arts, Culture (Mytilene 2010); Skordas, P., Ed.; Mytilene: Lesvos, Greece, 2011; pp. 129-147.

43. Torres, J.C.; Arroyo, G.; Romo, C.; Haro, J. De 3D Digitization using Structure from Motion. In Proceedings of the CEIG—Spanish Computer Graphics Conference, Jaén, Spain, 12-14 September 2012; pp. 1-10.

44. Westoby, M.J.J.; Brasington, J.; Glasser, N.F.F.; Hambrey, M.J.J.; Reynolds, J.M.M. Structure-from-Motion photogrammetry: A low-cost, effective tool for geoscience applications. Geomorphology 2012, 179, 300-314. [CrossRef]

45. Lowe, D.G. Distinctive Image Features from Scale-Invariant Keypoints. Int. J. Comput. Vis. 2004, 60, 91-110. [CrossRef]

46. Furukawa, Y.; Ponce, J. Accurate Camera Calibration from Multi-View Stereo and Bundle Adjustment. Int. J. Comput. Vis. 2009, 84, 257-268. [CrossRef]

47. Meier, L.; Tanskanen, P.; Fraundorfer, F.; Pollefeys, M. PIXHAWK: A system for autonomous flight using onboard computer vision. In Proceedings of the 2011 IEEE International Conference on Robotics and Automation, Shanghai, China, 9-13 May 2011; pp. 2992-2997.

48. Meier, L.; Tanskanen, P.; Fraundorfer, F.; Pollefeys, M. The PIXHAWK open-source computer vision framework for Mavs. ISPRS Int. Arch. Photogramm. Remote Sens. Spat. Inf. Sci. 2012, XXXVIII-1, 13-18. [CrossRef]

49. Mission Planner. Available online: http://ardupilot.org/ardupilot/index.html (accessed on 25 April 2019).

50. Agisoft LLC Agisoft PhotoScan. Prof. Ed. Version 1.4.1; Agisoft LLC: Petersburg, Russia, 2018.

51. Mathews, A.J.; Jensen, J.L.R. Visualizing and Quantifying Vineyard Canopy LAI Using an Unmanned Aerial Vehicle (UAV) Collected High Density Structure from Motion Point Cloud. Remote Sens. 2013, 5, 2164-2183. [CrossRef]

52. Dellaert, F.; Seitz, S.M.; Thorpe, C.E.; Thrun, S. Structure from motion without correspondence. In Proceedings of the IEEE Conference on Computer Vision and Pattern Recognition. CVPR 2000 (Cat. No.00662), Hilton Head Island, SC, USA, 15 June 2000.

53. Nex, F.; Remondino, F. UAV for 3D mapping applications: A review. Appl. Geomat. 2013, 6, 1-15. [CrossRef] 
54. Kourtzellis, Y. The Southern Harbour and the Commercial Stoa of the Hellenistic period. In Mytilene Unique Approaches; Myroyianni, Z., Ed.; Mytilene: Lesvos, Greece, 2013; pp. 11-15.

55. Topouzelis, K.; Papakonstantinou, A.; Doukari, M. Coastline change detection using Unmanned Aerial Vehicles and image processing technique. Fresenius. Environ. Bull. 2017, 26, 5564-5571.

56. Rock, G.; Ries, J.B.; Udelhoven, T. Sensitivity Analysis of Uav-Photogrammetry for Creating Digital Elevation Models (DEM). ISPRS Int. Arch. Photogramm. Remote Sens. Spat. Inf. Sci. 2011, XXXVIII-1/C22, 69-73. [CrossRef]

57. Salamí, E.; Barrado, C.; Pastor, E. UAV Flight Experiments Applied to the Remote Sensing of Vegetated Areas. Remote Sens. 2014, 6, 11051-11081. [CrossRef]

58. James, M.R.; Robson, S.; D'Oleire-Oltmanns, S.; Niethammer, U. Optimising UAV topographic surveys processed with structure-from-motion: Ground control quality, quantity and bundle adjustment. Geomorphology 2017, 280, 51-66. [CrossRef]

59. Watts, A.C.; Ambrosia, V.G.; Hinkley, E.A. Unmanned Aircraft Systems in Remote Sensing and Scientific Research: Classification and Considerations of Use. Remote Sens. 2012, 4, 1671-1692. [CrossRef]

60. Aicardi, I.; Nex, F.; Gerke, M.; Lingua, A. An Image-Based Approach for the Co-Registration of Multi-Temporal UAV Image Datasets. Remote Sens. 2016, 8, 779. [CrossRef]

61. Soulakellis, N.; Chatzistamatis, S.; Vasilakos, C.; Tataris, G.; Papakonstantinou, A.; Kavroudakis, D.; Topouzelis, K.; Roussou, O.; Kalloniatis, C.; Papadopoulou, E.E.; et al. Synergistic Exploitation of Geoinformation Methods for Post-Earthquake 3D Mapping of Vrisa Traditional Settlement, Lesvos Island, Greece. Int. Arch. Photogramm. Remote Sens. Spat. Inf. Sci. 2018, XLII-3/W4, 491-498.

62. Kavroudakis, D. Open Source Approach to Contemporary Research. In Open-Source Technologies for Maximizing the Creation, Deployment, and Use of Digital Resources and Information; IGI Global: Hershey, PA, USA, 2013; pp. 11-25.

(C) 2019 by the authors. Licensee MDPI, Basel, Switzerland. This article is an open access article distributed under the terms and conditions of the Creative Commons Attribution (CC BY) license (http://creativecommons.org/licenses/by/4.0/). 